\title{
SIW Based Cavity Backed Self-Quadplexing Slot Antenna
}

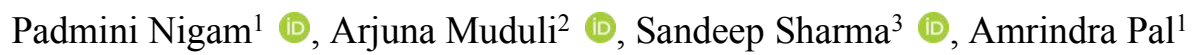 \\ ${ }^{1}$ ECE Dept.DIT University Dehradun INDIA, nigam242@gmail.com, amrindra.pal123@gmail.com \\ ${ }^{2}$ ECE Dept.K.L. deemed to be University, Andhra-Pradesh INDIA, arjunamuduli@gmail.com \\ ${ }^{3}$ Centre for Reliability Sciences and Technologies, Chang Gung University, Taoyuan, Taiwan \\ tek.learn@gmail.com
}

\begin{abstract}
In this paper, a low profile substrate integrated waveguide (SIW) based self-quadplexing antenna with high isolation is demonstrated for multiband wireless applications. Here the SIW based resonator cavity is integrated with an " $X$ "-shaped resonator and formed the four quarter mode cavities having the individual microstrip feed lines. Each quarter mode cavity consists of " $V$ "-shaped slots of different lengths; are in front to feed line and produce the four distinct resonant frequencies at $7.8 \mathrm{GHz}, 8.5 \mathrm{GHz}$, $10.2 \mathrm{GHz}$, and $10.6 \mathrm{GHz}$, respectively. The working principle depends upon the perturbation of higher-order modes in a particular quarter mode cavity. The minimum intrinsic isolation of below than -26dB is attained between any of the two input ports by adequately modifying the antenna dimensions. Hence, a single antenna consists of four individual signals without interfering with each other, which determines the self-quadplexing property of the antenna. The proposed antenna is realized for maximum efficiency and minimum value of frequency ratio. The measured gain of the proposed antenna is $4.5 \mathrm{dBi}, 5.28 \mathrm{dBi}, 7.1 \mathrm{dBi}$, and $7.4 \mathrm{dBi}$ at the four resonant frequencies, respectively.
\end{abstract}

Index Terms - Substrate Integrated Waveguide (SIW), Self-Quadplexing Antenna, Isolation, Quarter Mode (QM) Cavity.

\section{INTRODUCTION}

In recent years, accelerated advancement and rapid development are necessary for innovative antenna modules, autonomous satellite subsystems, as well as in radar vehicles; are highly required in the field of communication. In this, the dual and multiband antennas are generally used in several domains like- RFID, internet of things (IoT) based narrowband system, electro-optic system, and satellite services also [1, 2]. For this, a multiplexer (frequency decoupled) circuit with maximum selectivity for the co-existing signals and increased isolation value among ports is mainly required; thus, it adds to the size, cost, and complexity of the entire system [3]. Several techniques like defected ground structure (DGS) [4], double/ multilayer concept [5], and electromagnetic bandgap (EBG) structures [6] have been recommended to achieve better isolation performance. However, these techniques come with drawbacks like back radiation, increased size, fabrication, and integration complexity with planar circuits. The shared aperture technology is another unique technique to attain 
Journal of Microwaves, Optoelectronics and Electromagnetic Applications, Vol. 20, No. 3, September 2021 DOI: http://dx.doi.org/10.1590/2179-10742021v20i31213

dual/ multiband responses with good isolation [7, 8]. This concept is integrated with SIW methodology for its primary features like small footprints, ease to integrate, minimum losses, and cost-efficient than other approaches [9].

The SIW based self-diplexing and self-triplexing/ multiplexing antennas with the frequency tunability, stable gain, and enhanced isolation levels for multi-frequency operations are suggested in [10-22]. These can be easily integrated with RF front-end systems and reduce the extra circuitry of the decoupling elements as diplexer and triplexer. In [17], a self-triplexing antenna working at three resonating frequencies is presented with good in-band isolation $(<-26 \mathrm{~dB})$ performances, but the value of FTBR $(>15 \mathrm{~dB})$ and radiation efficiency $(<57 \%)$ are low. The work proposed in reference [15] describes the four bands operated self-quad-antenna with minimum isolation of $-23 \mathrm{~dB}$ and low value of gain $(<5.4 \mathrm{dBi})$ at operating frequency and [19] as compared to [18] is another self-quadplexing antenna having improved gain $(<7.4 \mathrm{dBi})$, and have reported the maximum radiation efficiency to be $>93 \%$ but the intrinsic isolation $(-22 \mathrm{~dB})$ has been reported only among the input ports. Isolation is the significant parameter for the self-quadplexing antenna to reduce the interference and mutual coupling among ports.

In this paper, a planar and shared aperture profile-based self-quadplexing antenna, dependent upon the higher mode perturbation concept of the individual resonating cavity, has a minimum frequency ratio. The proposed antenna operates at four different frequencies $(7.8 \mathrm{GHz}, 8.5 \mathrm{GHz}, 10.2 \mathrm{GHz}$, and $10.6 \mathrm{GHz}$ ) with minimum intrinsic isolation of $<-26 \mathrm{~dB}$, the minimum gain of $4.5 \mathrm{dBi}$, and narrow bandwidth of $2.75 \%$. The four resonating frequencies of the proposed antenna have been selected from the point of view of operating under harsh or distressed environments, for example, for disaster management team members working in a mixed environment with and without a connected network, so the resonating frequencies are a mix of frequencies that can be used for military application, in radars for target identification and as downlink frequency for satellite communication (7.8 GHz). ITU band applications and uplink frequency for satellite communication $(8.5 \mathrm{GHz})$, terrestrial, broadband services, and amateur satellite operation as downlink and uplink frequency $(10.2 \mathrm{GHz}$ and $10.6 \mathrm{GHz})$ with narrower bandwidth collectively these frequencies help keep the communications activities with these workers. It can also be used for military applications simultaneously. Various slot shapes like a rectangular, semicircle, and "I"-shaped are also simulated for obtaining the best results; it is observed that the "V"-shaped slot is the best choice.

\section{ANTENNA CONFIgURATION AND Working Principle}

The geometrical view of the shared aperture SIW based proposed self-quadplexing antenna is shown in Fig. 1. A rectangular SIW based resonant cavity is integrated with the "X"-shaped resonant cavity, and it is also arranged by the appropriate installation of the metallic vias. The proposed " $\mathrm{X}$ "shaped cavity is used to convert the SIW cavity into four distinct quarter mode (QM) resonating cavities. These QM cavities consist of 4 individual "V"-shaped radiate slots of different lengths and 
excited by separate microstrip feed lines of $50 \Omega$. These slots are radiated into free space at four distinct resonating frequencies.

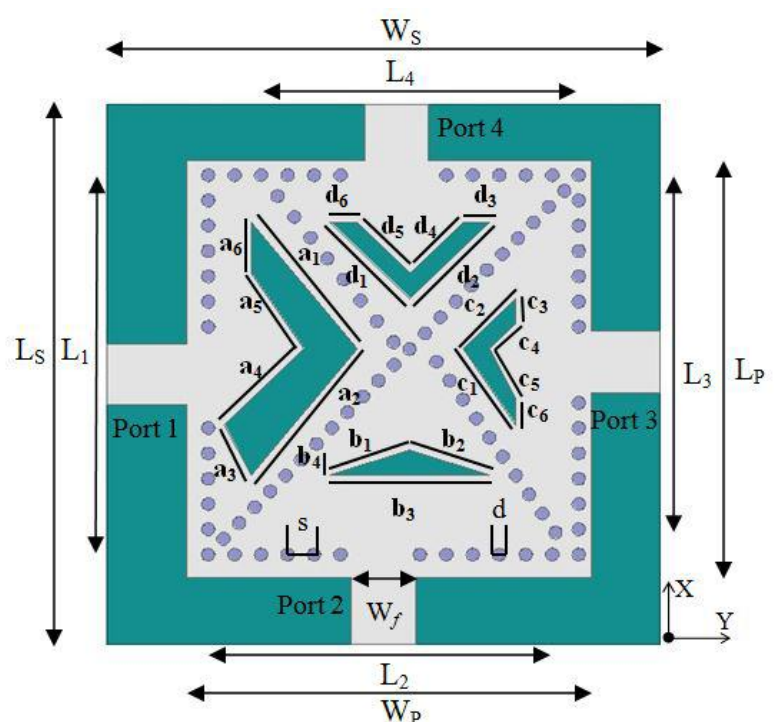

(a)

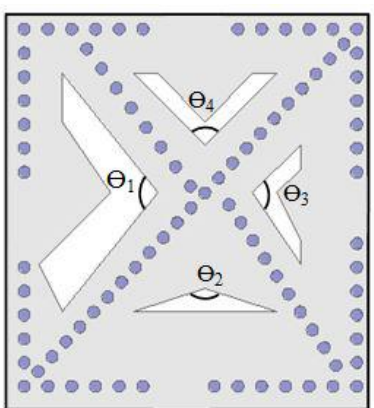

(b)

Fig. 1. (a) Geometrical view and (b) " $\Theta$ " values of each "V"-shaped slot of the proposed self-quadplexing antenna. $\left[\mathrm{L}_{\mathrm{S}}=42.7, \mathrm{~L}_{\mathrm{P}}=33.0, \mathrm{~W}_{\mathrm{S}}=41.7, \mathrm{~W}_{\mathrm{P}}=30.5, \mathrm{~L}_{1}=30, \mathrm{~L}_{2}=28, \mathrm{~L}_{3}=26.2, \mathrm{~L}_{4}=24, \mathrm{~W}_{\mathrm{F}}=4.84, \mathrm{~s}=2, \mathrm{~d}=1, \mathrm{a}_{1}=10, \mathrm{a}_{2}=10, \mathrm{a}_{3}=\right.$ $4, \mathrm{a}_{4}=6, \mathrm{a}_{5}=6, \mathrm{a}_{6}=4, \Theta_{1}=112^{\circ}, \mathrm{b}_{1}=6.8, \mathrm{~b}_{2}=6.8, \mathrm{~b}_{3}=12.2, \mathrm{~b}_{4}=3, \Theta_{2}=106^{\circ}, \mathrm{C}_{1}=6.5, \mathrm{C}_{2}=5.5, \mathrm{C}_{4}=3.5, \mathrm{C}_{5}=4, \mathrm{C}_{6}=2$, $\left.\Theta_{3}=90.5^{\circ}, d_{1}=5.5, d_{2}=5.5, d_{3}=2, d_{4}=3.5, d_{5}=3.5, d_{6}=2, \Theta_{4}=94^{\circ}\right]$ all in $\mathrm{mm}$.

\section{A. "X”-shaped Cavity Analysis}

The proposed "X"-shaped cavity is integrated into the primary SIW cavity and turned into the four distinct QM resonating cavities of different lengths and sizes. These QM cavities serve as electric and magnetic walls due to the metallic vias shown in Fig. 3. These cavities are fed by a $50 \Omega$ microstrip feed line and generate dominant mode $\left(\mathrm{TE}_{110}\right)$ and higher-order mode for a particular excited $\mathrm{QM}$ cavity simultaneously [20]. These working modes within the specific QM cavity are also generalized by equation (1) $[18,23]$. When port 1 is $\mathrm{ON}$, i.e., QM cavity 1 is excited, it produces dominating mode at $5.95 \mathrm{GHz}$ and higher-order mode $\left(\mathrm{TE}_{120}\right)$ at $9.57 \mathrm{GHz}$. Similarly, when the QM cavity 2, cavity 3 , and cavity 4 are excited simultaneously, the dominating modes are found at $6.4 \mathrm{GHz}, 6.82$ $\mathrm{GHz}$, and $7.46 \mathrm{GHz}$. In contrast, higher-order modes are obtained at $10.14 \mathrm{GHz}\left(\mathrm{TE}_{210}\right), 11.11 \mathrm{GHz}$ $\left(\mathrm{TE}_{210}\right)$, and $11.38 \mathrm{GHz}\left(\mathrm{TE}_{120}\right)$, respectively. These all are justified by the $|\mathrm{Z}|$-parameters of " $\mathrm{X}$ "cavity as shown in Fig. 2 and visualized by magnetic field distribution as displayed in Fig. 3.

For the QMSIW cavity $[18,23]-$

$$
f_{110, Q M}=\frac{c}{\sqrt{2 \pi \varepsilon_{r}}} \sqrt{\left(\frac{\pi}{2 L_{e f f}}\right)^{2}+\left(\frac{\pi}{2 L_{e f f}}\right)^{2}}
$$


For effective Length (Leff) of QMSIW cavity [24],

$$
L_{e f f}=L-\frac{d^{2}}{0.95 s} \quad \text { or, } \quad L_{e f f}=L-1.08 \frac{d^{2}}{s}+0.1 \frac{d^{2}}{L}
$$

$\mathrm{L}_{\text {eff }}$ is the effective length of the particular QM cavity; as for QM cavity 1, the linear length $L$ is $\mathrm{L}_{1}$ and length $\mathrm{L}_{2}, \mathrm{~L}_{3}$, and $\mathrm{L}_{4}$ related to length $L$ for QM cavity 2, QM cavity 3, and QM cavity 4, respectively in equation 2 [24].

\section{B. Self-quadplexer Antenna Analysis}

The operating principle of the proposed shared aperture-based SIW antenna is dependent on the perturbation of the higher-order mode, i.e., $\mathrm{TE}_{120}, \mathrm{TE}_{210}$ of the particular $\mathrm{QM}$ cavity into the resonating mode cavity at a specific frequency. The mode perturbation belongs to the slot-loading effect with the advantages of high gain, maximum efficiency, and better bandwidth [25]. Each QM cavity consists of a "V"-shaped slot that leads to the shape of an individual QM cavity and radiates efficiently into free space without any leakage of energy [26]. These radiated slots are in front of the respective feed lines and block the electromagnetic waves from transmitting into another cavity. If the slot length changes then it provides the change in resonant frequency. If the interior angle $(\Theta)$ of the respective "V"-slot decreases, this leads to sharper the Q-factor with narrower impedance bandwidth. As the width of the slot increases, Q-factor decreases.

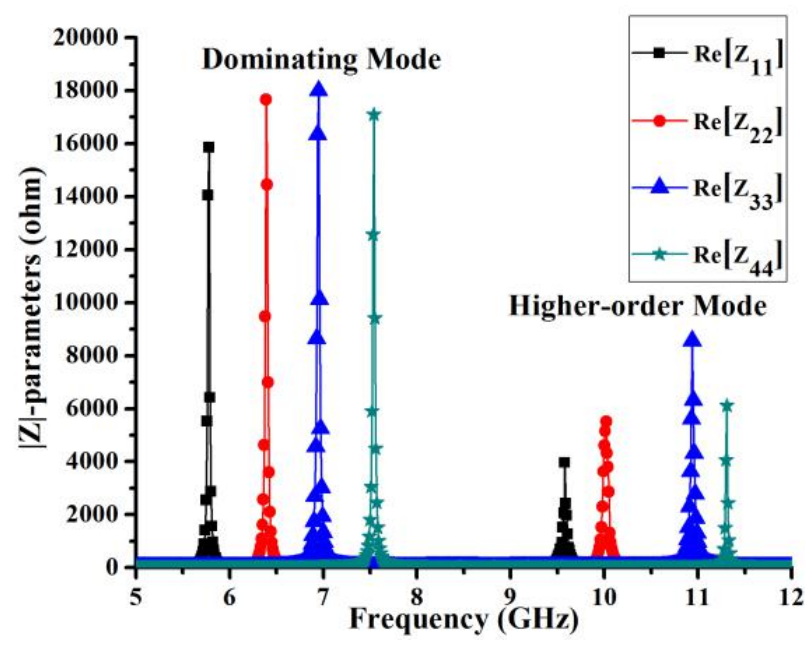

Fig. 2. $|\mathrm{Z}|$-parameters of the proposed $\mathrm{X}$-shaped cavity. 


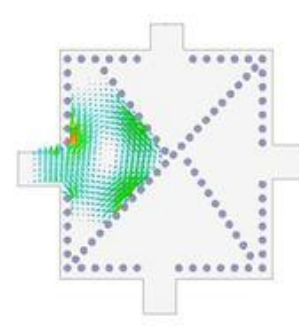

(a)

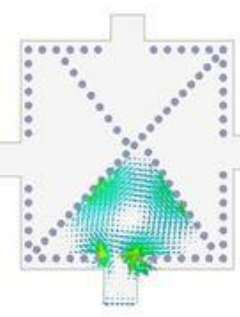

(b)

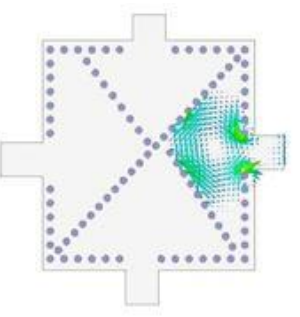

(c)

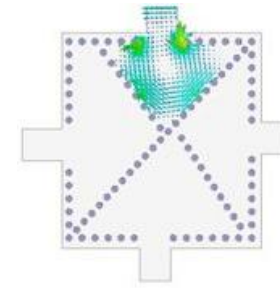

(d)

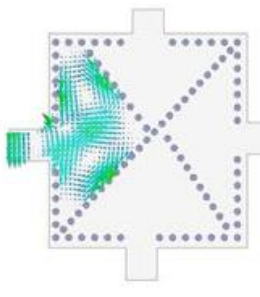

(e)

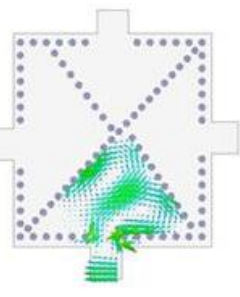

(f)

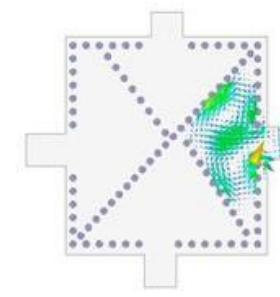

(g)

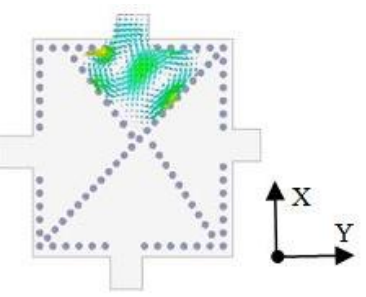

(h)

Fig. 3. The Magnetic field distribution in X-cavity as dominating mode (TE 110 ) at (a) $5.95 \mathrm{GHz}$, (b) $6.4 \mathrm{GHz}$, (c) $6.82 \mathrm{GHz}$, (d) 7.46GHz, and high-order modes (TE $120, \mathrm{TE}_{210}$ ) at (e) $9.57 \mathrm{GHz}$, (f) $10.14 \mathrm{GHz},(\mathrm{g}) 11.11 \mathrm{GHz}$, and (h) $11.38 \mathrm{GHz}$.

When port 1 is on, the higher-order mode of QM cavity-1 at $9.57 \mathrm{GHz}$ gets perturbed towards the first resonant frequency at $7.8 \mathrm{GHz}$. The size of the slot-1 is larger than each other slots; due to this loading effect is the maximum around slot-1 [27]. Similarly, the port 2 is on, the higher-order mode of QM cavity-2 at $10.14 \mathrm{GHz}$ gets perturbed towards the second resonant frequency at $8.5 \mathrm{GHz}$ of the proposed antenna, but it is also the first resonance for the QM cavity-2. Likewise, when port 3 and port 4 are excited, the higher-order mode of QM cavity-3 at $11.11 \mathrm{GHz}$ and higher-order mode of QM cavity-4 at $11.38 \mathrm{GHz}$ gets perturbed third and fourth resonant frequency at $10.2 \mathrm{GHz}$ and $10.6 \mathrm{GHz}$, respectively of the presented self-quadplexing antenna. However, these resonating frequencies as 10.2 $\mathrm{GHz}$ and $10.6 \mathrm{GHz}$ are also the first operating mode for their specific QM cavities as QM cavity-3 and QM cavity-4, individually. This operating principle is justified by the $|\mathrm{Z}|$-parameters as displayed in Fig. 4. The distribution of surface current in the respective radiating slots is defined in Fig. 5(a) to 5 (d) at each operating frequency.

When port 1 is excited at $7.8 \mathrm{GHz}$, the surface current becomes leading on the area of QM cavity 1, and most of the current is flowing around the boundary of the first "V"-shaped slot. Despite this, the surface current is insignificant ( $\approx$ zero) at the range of other slots shown in vector form in Fig. 5(a). When port 2 is on, the surface current is spreading over the vicinity of " $\mathrm{V}$ " slot 2 only; however, the remaining slots do not affect, as displayed in Fig. 5(b). Similarly, when port 3 and port 4 are excited 
Journal of Microwaves, Optoelectronics and Electromagnetic Applications, Vol. 20, No. 3, September 2021 DOI: http://dx.doi.org/10.1590/2179-10742021v20i31213

simultaneously at frequencies $10.2 \mathrm{GHz}$ and $10.6 \mathrm{GHz}$, the surface current is highly concentrated over the boundary space of "V" slot 3 and slot 4, respectively, as shown in Fig. 5(c) and 5(d). In contrast, the effect on the rest of the slots is ignored.

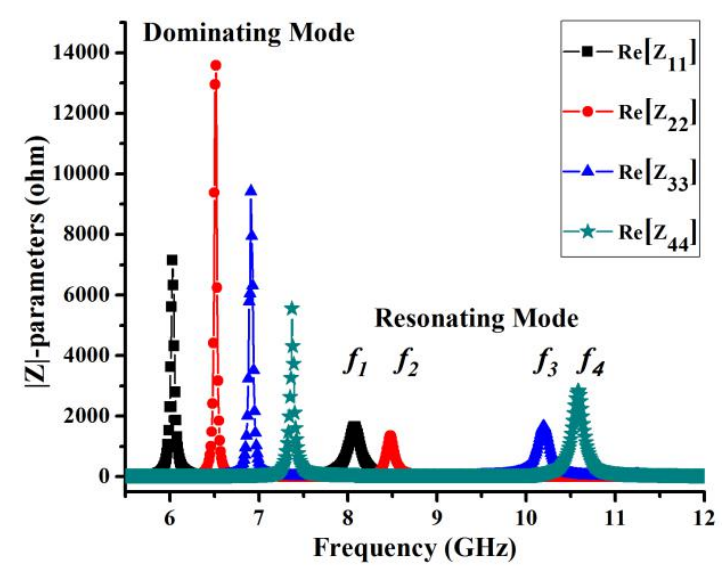

Fig. 4. $|\mathrm{Z}|$-parameters of the proposed self-quadplexing antenna geometry.

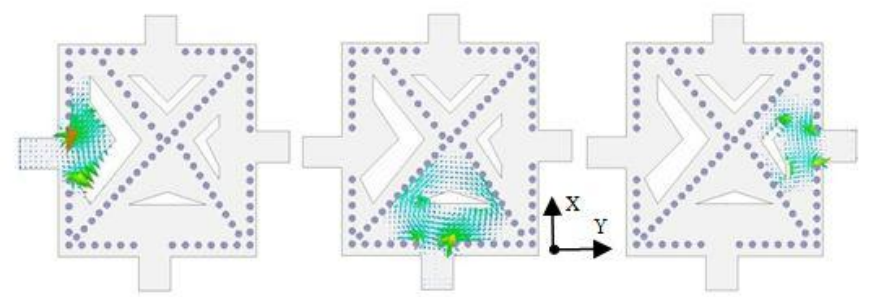

(a)

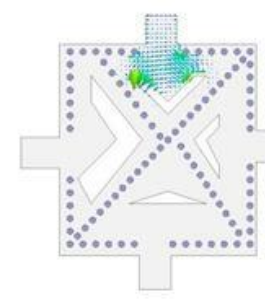

(d) (b)

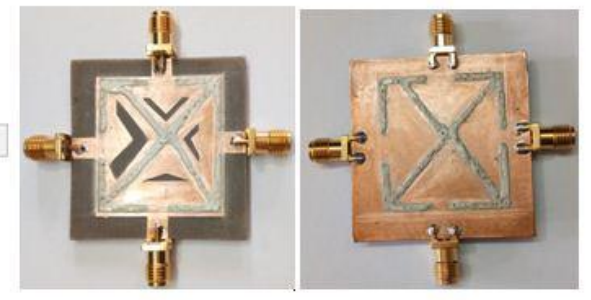

(e)

(f)

Fig. 5. The magnetic field distribution at resonant frequencies, (e) top and (f) rear view of the proposed self-quadplexing antenna.

\section{Equivalent Circuit Model Analysis}

The equivalent circuit model of the proposed self-quadplexing antenna is shown in Fig. 6. Each port of impedance $50 \Omega$ is connected with a parallel RLC network, produces maximum impedance, and works as a rejecter circuit for all frequencies except resonant frequency with a narrower bandwidth. The Q-factor of each network depends upon the "V"-shaped slot width; as the slot width decreases, sharpness in Q-factor due to the decrement in inductance and gain in capacitance. The maximum Qfactor is obtained at the third and fourth resonant frequency because the width of slot- 3 and slot- 4 is less than slot-1 and slot-2. The mutual coupling among four ports is formed by the LC network [28]. 
Journal of Microwaves, Optoelectronics and Electromagnetic Applications, Vol. 20, No. 3, September 2021 DOI: http://dx.doi.org/10.1590/2179-10742021v20i31213

Here, inter-mutual coupling among input ports is represented by $\mathrm{MC}_{12}, \mathrm{MC}_{23}, \mathrm{MC}_{34}, \mathrm{MC}_{13}, \mathrm{MC}_{24}$, and $\mathrm{MC}_{14}$; mutual coupling between port 1 and port 2. To optimize all values of each network component, the Keysight Advanced Design System (ADS) software was used, and RLC values are given in Table I. The graphical representation of S-parameters obtained by ADS software in terms of return loss and isolation of the equivalent circuit model is presented in Fig. 7. With the help of each RLC network, the four resonating frequencies are found at $7.8 \mathrm{GHz}, 8.5 \mathrm{GHz}, 10.2 \mathrm{GHz}$, and $10.6 \mathrm{GHz}$, respectively, along with minimum intrinsic isolation of below than $-26.3 \mathrm{~dB}$. It also provides an excellent agreement with simulated results by another electromagnetic wave software HFSS as displayed in Fig. 12.

TABLE I. RLC and LC values [R in $\mathrm{K} \Omega, \mathrm{L}$ in $\mathrm{nH}, \mathrm{C}$ in $\mathrm{pF}]$

\begin{tabular}{cccc}
\hline $\mathrm{R}_{1}=3.41$ & $\mathrm{~L}_{12}=24.7$ & $\mathrm{R}_{3}=9.3$ & $\mathrm{~L}_{14}=31.25$ \\
\hline $\mathrm{L}_{1}=0.95$ & $\mathrm{C}_{12}=1.23$ & $\mathrm{~L}_{3}=0.47$ & $\mathrm{C}_{14}=0.635$ \\
\hline $\mathrm{C}_{1}=0.46$ & $\mathrm{~L}_{23}=26.68$ & $\mathrm{C}_{3}=0.54$ & $\mathrm{~L}_{13}=28.97$ \\
\hline $\mathrm{R}_{2}=3.5$ & $\mathrm{C}_{23}=0.84$ & $\mathrm{R}_{4}=7.5$ & $\mathrm{C}_{13}=0.65$ \\
\hline $\mathrm{L}_{2}=0.73$ & $\mathrm{~L}_{34}=29.72$ & $\mathrm{~L}_{4}=0.38$ & $\mathrm{~L}_{24}=30.12$ \\
\hline $\mathrm{C}_{2}=0.49$ & $\mathrm{C}_{34}=0.79$ & $\mathrm{C}_{4}=0.595$ & $\mathrm{C}_{24}=0.59$
\end{tabular}

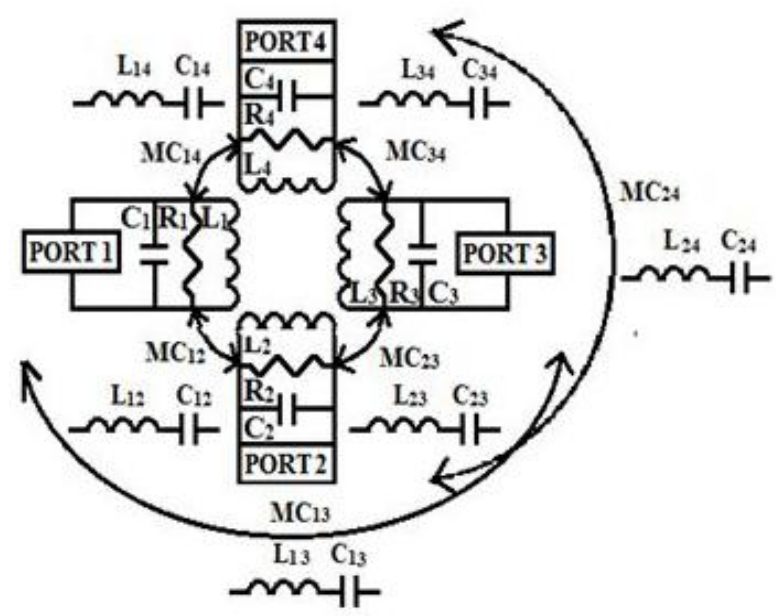

Fig. 6. The equivalent circuit model of the proposed self-quadplexing antenna.

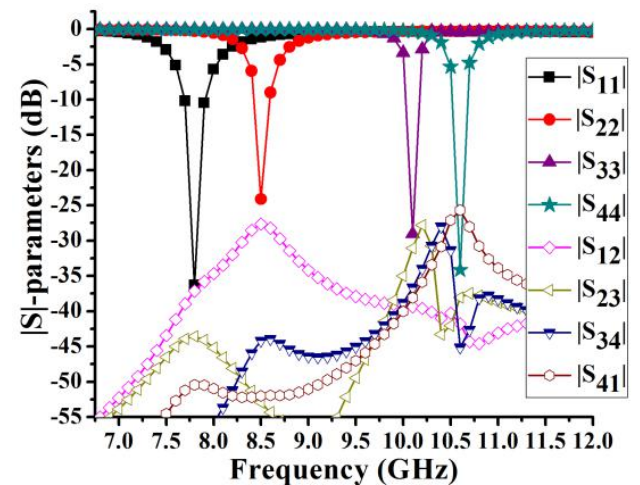

Fig. 7. S-parameters of the equivalent circuit model for proposed self-quadplexer antenna. 
Journal of Microwaves, Optoelectronics and Electromagnetic Applications, Vol. 20, No. 3, September 2021 DOI: http://dx.doi.org/10.1590/2179-10742021v20i31213

\section{D. $\quad$ Significance of " $X$ "-shaped Resonant Cavity}

Isolation and gain parameters are the essential features of any antenna for good in-band performance. Here comparison has been made for both with as well as without "X"-cavity structures, the antenna with "X"-cavity has the better outcomes in terms of isolation $(<-26 \mathrm{~dB})$ and gain $(>4.5$ $\mathrm{dBi})$ values than without "X"-cavity where the values of isolation $(<-10 \mathrm{~dB})$ and gain $(>2.13 \mathrm{dBi})$ is less. The geometrical structure is shown in Fig. 8, and the analysis of the antenna without the "X"cavity is defined by Fig. 9 and Fig. 10 in respect of S-parameters and gain.

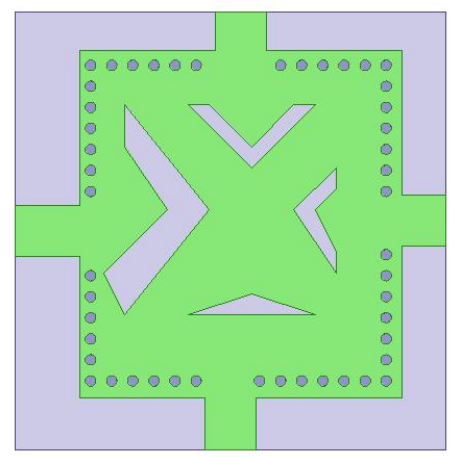

Fig. 8 - The proposed quadplexer antenna without "X"-shaped cavity.

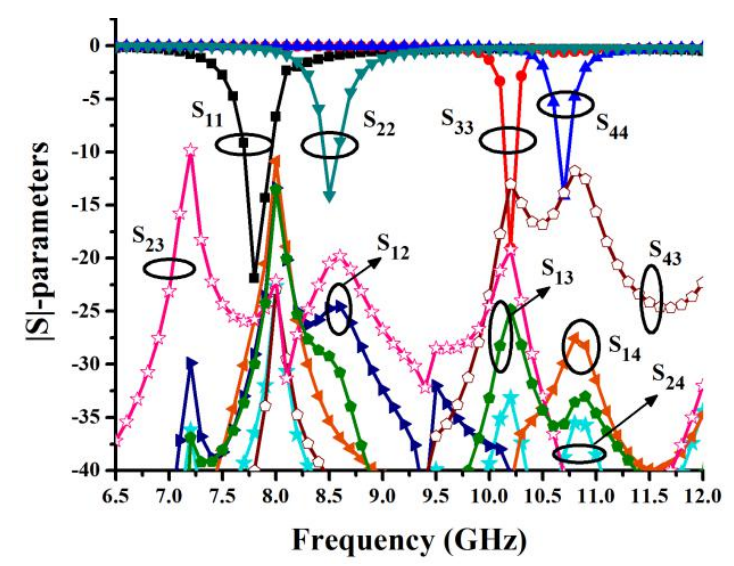

Fig. 9- The S-parameters of the proposed antenna without "X" cavity.

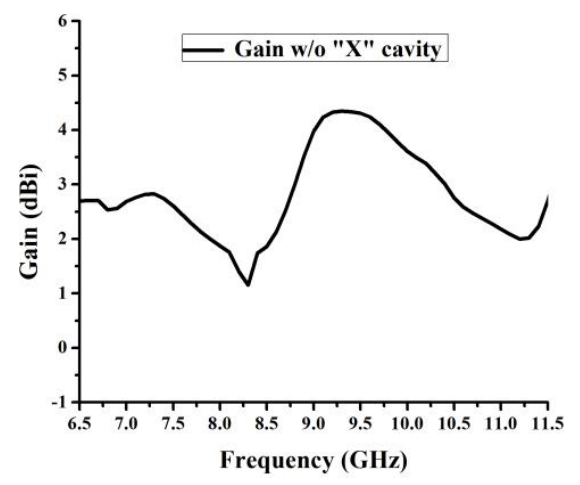

Fig. 10 - The gain of the proposed antenna without "X" cavity. 
Journal of Microwaves, Optoelectronics and Electromagnetic Applications, Vol. 20, No. 3, September 2021

DOI: http://dx.doi.org/10.1590/2179-10742021v20i31213

So, the structure with "X"-cavity is preferred because of negligible interference of electromagnetic waves among QMSIW cavities as shown in Fig. 2 and Fig. 3; thus, improved isolation and enhanced gain are achieved. Due to the self-quadplexing antenna, communication among four operating bands without interference is mainly needed [29].

\section{E. Designing Steps and Parametric study}

The proposed quad-band antenna resonates at four operating frequencies, like $7.8 \mathrm{GHz}, 8.5 \mathrm{GHz}$, 10.2 GHz, and 10.6 GHz for X-band application. Here, the following design ideas are recommended in short as point form.

1. Choose the dimension of the SIW cavity, i.e., $L_{P}$ for the dominating mode (TE 10$)$ operates within the X-band.

2. Implement the "X"-shaped cavity and converted the SIW cavity into four QM resonating cavities of distinct length, i.e., $L_{1}, L_{2}, L_{3}$, and $L_{4}$, respectively.

3. Each QM cavity has dominant mode and higher-order mode, explained by equation (1) and $|\mathrm{Z}|-$ parameters shown in Fig. 2 and justified by magnetic field distribution as displayed in Fig. 3.

4. The "V"-shaped slots are etched over the metallic plane of each QM cavity, and the length of the radiated slot depends on half of the free space wavelength $\left(\lambda_{0} / 2\right)$ at the particular resonant frequency.

5. Optimized the total slot length i.e. $\left\{\left(a_{1}+a_{2}\right),\left(b_{1}+b_{2}\right),\left(c_{1}+c_{2}\right)\right.$, and $\left.\left(d_{1}+d_{2}\right)\right\}$ for the good reflection and better isolation $<-26 \mathrm{~dB}$.

6. Optimized the slot width $\left(a_{3}, b_{4}, c_{3}\right.$, and $\left.d_{3}\right)$ and interior angle $(\theta)$ of the "V" slots for the betterment of the fractional bandwidth of the resonant frequency.

7. Repeat the last two steps for the well-applicable results.

Different slot shapes like rectangular, semicircle, and "I"-shaped are also simulated. It is observed that the "V"-shaped slot has the best-simulated results; in terms of minimum reflection, maximum isolation with better frequency tunability at the resonant frequency as given in Table II.

TABLE II. COMPARISON AMONG THE DIFFERENT SHAPES OF THE SLOT

\begin{tabular}{cccc}
\hline Slot Shape & $\begin{array}{c}\text { Minimum Reflection } \\
\text { coefficient (dB) }\end{array}$ & $\begin{array}{c}\text { Minimum Isolation } \\
(\mathbf{d B})\end{array}$ & $\begin{array}{c}\text { Maximum Frequency } \\
\text { Tunability (GHz) }\end{array}$ \\
\hline Rectangular Slot & $<-19$ & $<-17.3$ & $<0.45$ \\
Semi-circle Slot & $<-21$ & $<-20$ & $<0.41$ \\
"I"-shaped slot & $<-23$ & $<-18.7$ & $<0.46$ \\
"V"-shaped slot & $<-27$ & $<-26$ & $<0.54$ \\
\hline
\end{tabular}

The parametric analysis of the proposed quad-band antenna is explained in three ways; change in the length, width, and interior angle of the "V"-shaped slots. The property of the frequency tunability is fully dependent upon the length of the "V" slot, and an inverse relation is maintained between the Brazilian Microwave and Optoelectronics Society-SBMO received 13 Feb 2021; for review 25 Feb 2021 ; accepted 30 May 2021 Brazilian Society of Electromagnetism-SBMag $\quad$ C 2021 SBMO/SBMag $\quad$ (cc)) BY 
resonant frequency and length of the slot, as shown in Fig. 11(a). As the slot length increases, the first "V" slot as $\mathrm{V}_{1}=\left(\mathrm{a}_{1}+\mathrm{a}_{2}\right)$ can be tuned from the range of $18 \mathrm{~mm}$ to $21.5 \mathrm{~mm}$, and as a result, the frequency can be tuned from the vicinity of $7.64 \mathrm{GHz}$ to $8.18 \mathrm{GHz}$. Likewise, the length of the second "V" slot $\mathrm{V}_{2}=\left(\mathrm{b}_{1}+\mathrm{b}_{2}\right)$ can be tuned from the range of $12.5 \mathrm{~mm}$ to $15 \mathrm{~mm}$, and as a result, the frequency can be adjusted from the vicinity of $8.37 \mathrm{GHz}$ to $8.64 \mathrm{GHz}$. The third resonant frequency can be tuned from $9.94 \mathrm{GHz}$ to $10.58 \mathrm{GHz}$ by the change in slot length $\mathrm{V}_{3}=\left(\mathrm{c}_{1}+\mathrm{c}_{2}\right)$ from $10.5 \mathrm{~mm}$ to $13 \mathrm{~mm}$. Similarly, the fourth resonant frequency can be tuned from $10.52 \mathrm{GHz}$ to $10.78 \mathrm{GHz}$ by the change in slot length $\mathrm{V}_{4}=\left(\mathrm{d}_{1}+\mathrm{d}_{2}\right)$ from $9.5 \mathrm{~mm}$ to $12 \mathrm{~mm}$ as displayed in Fig. 11(a). Fig. 11(b) describes the relationship between the variation in slot width and its effect on the proposed antenna's impedance bandwidth. It is observed that the slot width and impedance bandwidth has a proportional relation to each other. As the slot width increases, the bandwidth also increases, as shown in Fig. 11(b). Here, the slot widths are in increasing order, i.e., the width of the slot $1\left(a_{3}\right)$ is greater than the width of slot $\left(b_{4}\right)$, slot $3\left(c_{3}\right)$, and slot $4\left(d_{3}\right)$ as a result; the impedance bandwidth of first resonant frequency is higher than others.

Similarly, the bandwidth at the second resonant frequency is more than the third and fourth resonant frequency. A bold line easily defines this in Fig.11 (b). This correlation is also justified by the help of equivalent circuit model analysis in a previous sub-section.

The relation between the interior angle of the "V"-shaped slots with respect to the impedance bandwidth is demonstrated in Fig. 11 (c).

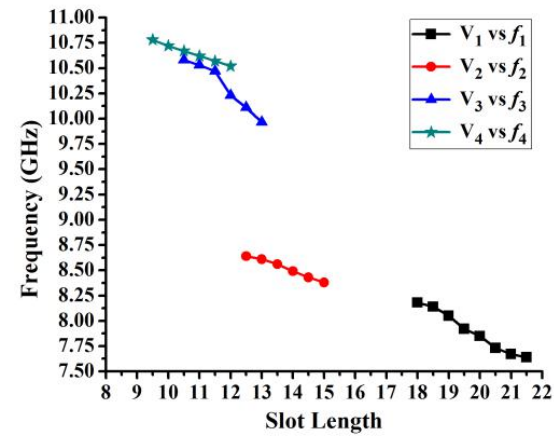

(a)

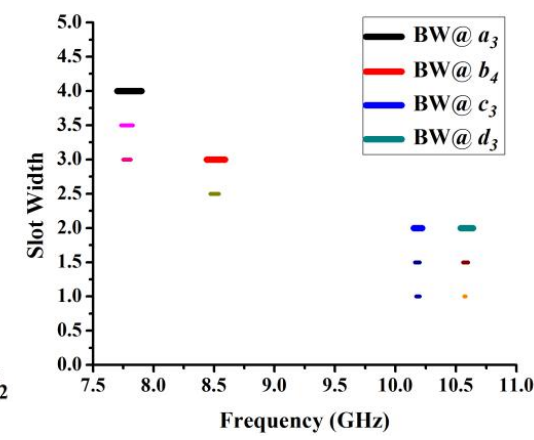

(b)

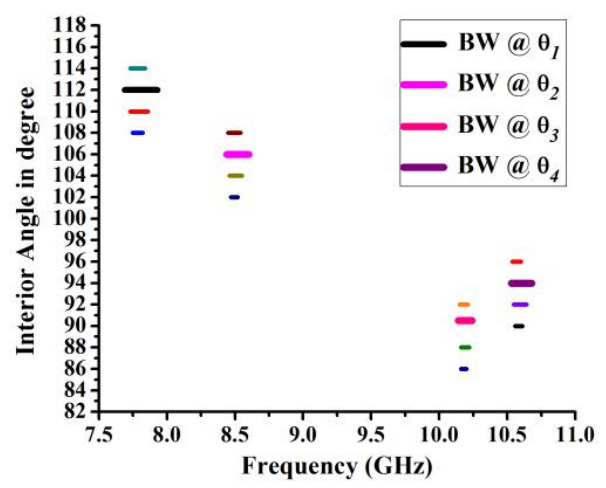

(c)

Fig. 11. Variation in "V"-shaped (a) slot length, (b) Slot width, and (c) slot interior angle with respect to the frequencies of the proposed antenna.

Brazilian Microwave and Optoelectronics Society-SBMO received 13 Feb 2021; for review 25 Feb 2021; accepted 30 May 2021 
Journal of Microwaves, Optoelectronics and Electromagnetic Applications, Vol. 20, No. 3, September 2021 DOI: http://dx.doi.org/10.1590/2179-10742021v20i31213

When the value of the interior angle $(\Theta)$ increases, the impedance bandwidth also increases at a certain point, as displayed in Fig. 11 (c). The value of the interior angle of the first "V" slot $\left(\theta_{1}=112^{\circ}\right)$ is higher than others; that leads toward maximum impedance bandwidth of $0.21 \mathrm{GHz}$. The interior angle is directly proportional to the bandwidth of the resonant frequency i.e. $\theta_{1}>\theta_{2}>\theta_{4}>\theta_{3}$ leads to $\mathrm{BW}_{1}>\mathrm{BW}_{2}>\mathrm{BW}_{4}>\mathrm{BW}_{3}\left[112^{\circ}>106^{\circ}>94^{\circ}>90.5^{\circ} \rightarrow 0.21 \mathrm{GHz}>0.14 \mathrm{GHz}>0.11 \mathrm{GHz}>0.05 \mathrm{GHz}\right]$. These proposed narrow bandwidths can be easily used for target identification in military services, advanced surveillance systems, and IoT-based systems.

\section{EXPERIMENTAL RESULTS}

In the manner to define the justification of the simulated design, the proposed self-quadplexing antenna structure was fabricated by using the Rogers RT/Duroid $5880\left(\varepsilon_{\mathrm{r}}=2.2, \tan \delta=0.0009\right.$, and thickness $\mathrm{t}=1.57 \mathrm{~mm}$ ) as shown in Fig. 5(e) and 5(f) and various results are measured such as $\mathrm{S}$ parameters, radiation pattern, gain, and efficiency. The S-parameters of the proposed antenna is measured by vector network analyzer (VNA) Agilent TN5247A. A very close agreement between simulated and measured results is presented in Fig. 12. The simulated (and measured peak) at the operating frequencies of $7.8 \mathrm{GHz}(7.86 \mathrm{GHz}), 8.5 \mathrm{GHz}(8.57 \mathrm{GHz}), 10.2 \mathrm{GHz}(10.22 \mathrm{GHz}), 10.6 \mathrm{GHz}$ $(10.55 \mathrm{GHz})$ with the measured absolute impedance bandwidth of $0.21 \mathrm{GHz}, 0.14 \mathrm{GHz}, 0.05 \mathrm{GHz}$, and $0.11 \mathrm{GHz}$ is obtained. Here each port is excited simultaneously, and others are terminated by 50 $\Omega$ matched load. The simulated and measured port isolation is $-41.1 \mathrm{~dB}(-34 \mathrm{~dB}),-33.89 \mathrm{~dB}(-27.2$ $\mathrm{dB}),-29.4 \mathrm{~dB}(-26.57 \mathrm{~dB})$, and $-28.4 \mathrm{~dB}(-26.25 \mathrm{~dB})$ is attained at resonating frequency simultaneously. The overall isolation among input ports is better than $-26 \mathrm{~dB}$ is achieved, which is observed as an attractive module for self-quadplexing technology. The S- parameters results of the fabricated structure were found in close agreement with the equivalent circuit model simulated by ADS software. The radiation pattern of the proposed antenna is measured by using the anechoic chamber, which shows the immediate concern with simulated counterparts. The simulated and measured radiation pattern of the antenna at four working frequencies with two fundamental planes at $\varphi=0^{\circ}$ and $\varphi=90^{\circ}$ are displayed and compared in Fig. 14 (a) to 14 (d). Both radiation patterns (simulated and measured) are stable and uni-directional at each resonating frequency. The measured values of FTBR are as $21.5 \mathrm{~dB}, 20.68 \mathrm{~dB}, 23.3 \mathrm{~dB}, 21.2 \mathrm{~dB}$ and the unwanted radiation i.e. crosspolarization are $-21.3 \mathrm{~dB},-25 \mathrm{~dB},-22.2 \mathrm{~dB},-22.75 \mathrm{~dB}$ at all working frequencies respectively. The simulated and measured peak gains are $4.9 \mathrm{dBi}(4.5 \mathrm{dBi}), 5.5 \mathrm{dBi}(5.3 \mathrm{dBi}), 7.4 \mathrm{dBi}(7.1 \mathrm{dBi})$, and 8.5 $\mathrm{dBi}(7.4 \mathrm{dBi})$ for exciting port1, port 2, port 3 and port 4 respectively given in Fig. 13 (a). The simulated and measured normalized radiation efficiencies are 0.91(0.83), 0.92(0.86), 0.94(.863), and 0.97(0.872) at each resonating frequency, respectively, as shown in Fig. 13(b). The comparison of features in terms of frequency ratio, gain, isolation, etc., among existing work like self-quadplexer/ self-triplexer and the proposed system, is given in tabular format as Table III. 


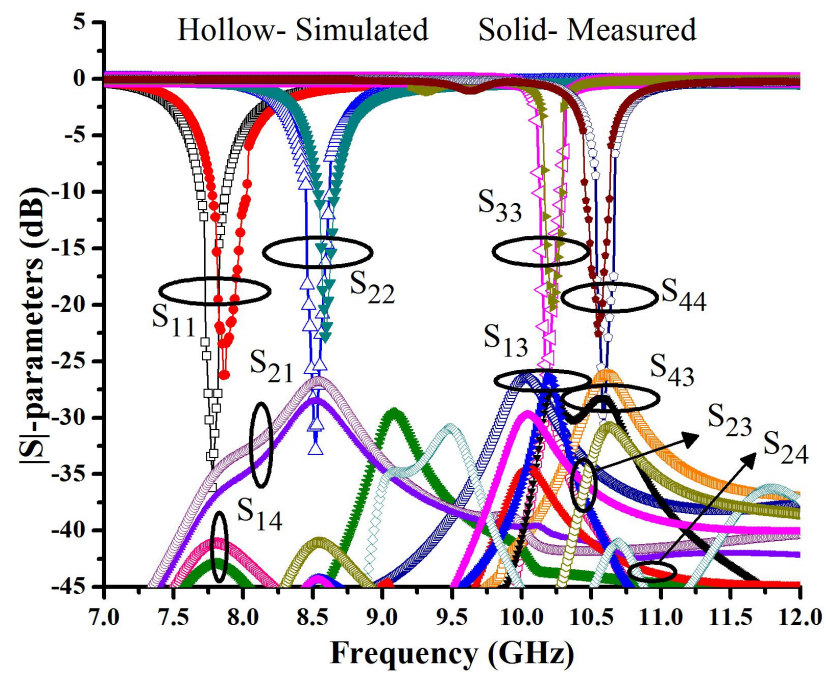

Fig. 12. The measured and simulated value of reflection coefficient and isolation of the proposed antenna.

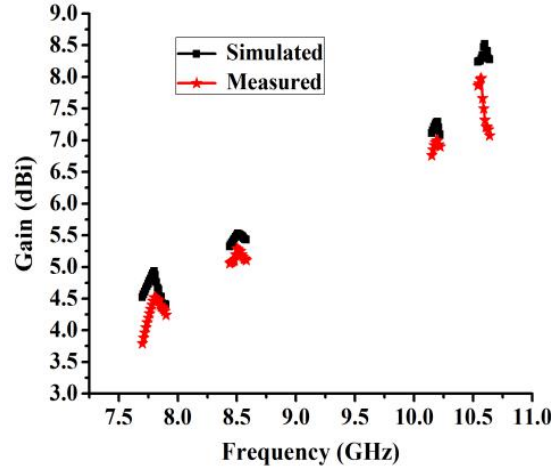

(a)

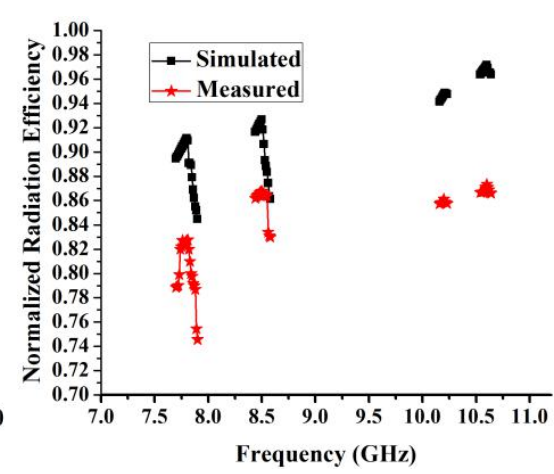

(b)

Fig. 13 The simulated and measured value of (a) gain and (b) normalized radiation efficiency of the proposed antenna

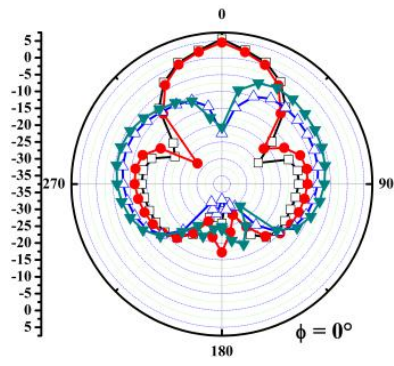

(a)

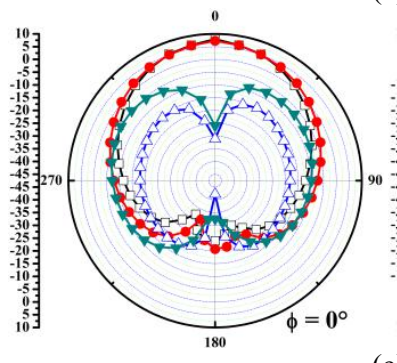

(c)

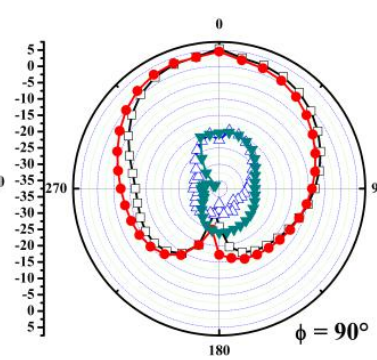

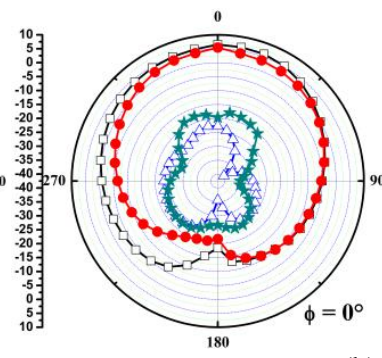

(b)
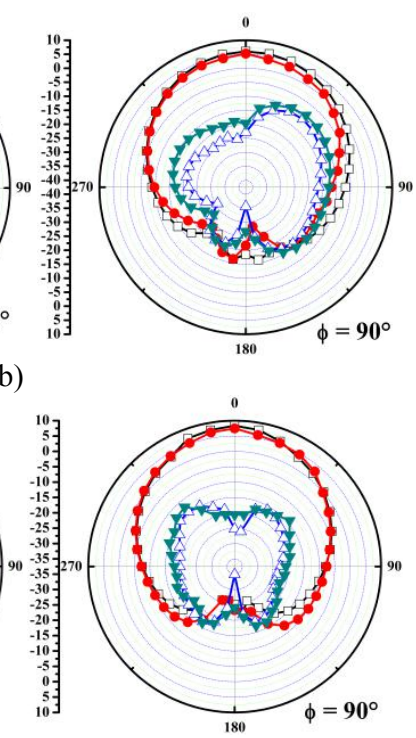

(d)

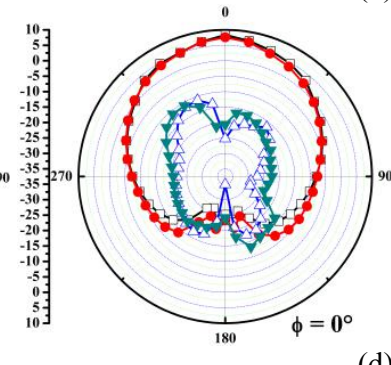

$\neg-$ Sim. Co-Pol. $\rightarrow$ Meas. Co-Pol. $\rightarrow$ Sim. X-Pol. $\rightarrow$ Meas. X-Pol.

Fig.14. The measured and simulated value of radiation pattern at $\varphi=0^{\circ}$ and $\varphi=90^{\circ}$ (a) at $7.8 \mathrm{GHz}$ (Port 1 is $\left.\mathrm{ON}\right),(\mathrm{b})$ at 8.5 $\mathrm{GHz}$ (Port 2 is $\mathrm{ON}),(\mathrm{c})$ at $10.2 \mathrm{GHz}$ (Port 3 is $\mathrm{ON}$ ) and (d) at $10.6 \mathrm{GHz}$ (Port 4 is ON). 
Journal of Microwaves, Optoelectronics and Electromagnetic Applications, Vol. 20, No. 3, September 2021 DOI: http://dx.doi.org/10.1590/2179-10742021v20i31213

TABLE III. COMPARISON WITH EXISTING SELF-QUADPLEXING AND SELF-TRIPLEXING ANTENNAS

\begin{tabular}{|c|c|c|c|c|}
\hline Features/ [Ref.] [Year] & $\begin{array}{l}\text { Proposed } \\
\text { Work }\end{array}$ & [19] [2019] & {$[18][2019]$} & {$[16][2020]$} \\
\hline \multirow{4}{*}{$\begin{array}{c}\text { Resonant } \\
\text { Frequency }(\mathrm{GHz})\end{array}$} & 7.8 & 8.19 & 3.5 & 3.5 \\
\hline & 8.5 & 8.8 & 5.2 & 4.8 \\
\hline & 10.2 & 9.71 & 5.5 & 5.4 \\
\hline & 10.6 & 11 & 5.8 & - \\
\hline Frequency Ratio & $1.08,1.03$ & $1.08,1.13$ & $1.48,1.05$ & $1.37,1.12$ \\
\hline Minimum Isolation (dB) & $<-26$ & $<-22$ & $<-23.6$ & $<-26$ \\
\hline $\begin{array}{l}\text { Minimum Cross-polarization, } \\
\text { and FTBR }(\mathrm{dB})\end{array}$ & $<-21$, and $>20$ & $\begin{array}{l}<-24.7, \text { and } \\
\quad>18.2\end{array}$ & N.A. & $\begin{array}{l}\text { N.A., and } \\
>16.1\end{array}$ \\
\hline Fractional Bandwidth (\%) & $\begin{array}{l}2.57,1.3 \\
0.78,0.96\end{array}$ & $2.8,1.9,3,2$ & N.A. & $\begin{array}{c}0.57,0.84 \\
0.37 \\
\end{array}$ \\
\hline Gain (dBi) & $\begin{array}{c}4.5,5.3,7.1 \\
7.4 \\
\end{array}$ & $\begin{array}{c}5.5,6.9,7.47 \\
7.45 \\
\end{array}$ & $\begin{array}{l}5.43,4.1 \\
3.56,3.6\end{array}$ & $4.5,5.9,6$ \\
\hline $\begin{array}{c}\text { Size }\left(\lambda_{L^{-}} \text {lower resonating }\right. \\
\text { wavelength) }\end{array}$ & $1.6 \lambda_{L} \times 1.6 \lambda_{L}$ & $1.5 \lambda_{L} \times 1.5 \lambda_{L}$ & N.A. & $0.7 \lambda_{L} \times 0.7 \lambda_{L}$ \\
\hline Type & $\begin{array}{c}\text { Self- } \\
\text { quadplexer }\end{array}$ & $\begin{array}{c}\text { Self- } \\
\text { quadplexer }\end{array}$ & $\begin{array}{c}\text { Self- } \\
\text { quadplexer }\end{array}$ & Self-triplexer \\
\hline
\end{tabular}

FTBR $=$ Front to back ratio

NA- Not available

\section{CONCLUSION}

The features of the fabricated Self-quadplexing antenna are integrated with assets of a planar, and the conventional cavity antenna is demonstrated in this research paper. The proposed antenna is based upon shared aperture topology and operates at four distinct resonant frequencies with the minimum measured isolation of $<-26 \mathrm{~dB}$. These resonant frequencies share a minimum frequency ratio and are generally used in wireless, radar, and satellite communication networks. The proposed antenna is planar in that way; the rear (ground) portion can be further used for the system in package (SiP) technology. The proposed antenna possessed better cross-polarization $(<-21 \mathrm{~dB})$, high normalized efficiency $(>0.83)$, good FTBR $(>20 \mathrm{~dB})$ and minimum gain of $4.5 \mathrm{dBi}$ with uni-directional radiation patterns.

\section{REFERENCES}

[1] H. Huang, Y. Liu, S. Zhang and S. Gong, "Multiband Metamaterial-Loaded Monopole Antenna for WLAN/WiMAX Applications," in IEEE Antennas and Wireless Propagation Letters, vol. 14, pp. 662-665, 2015.

[2] N. Kumar, R. Khanna, "A compact multiband multi-input multi-output antenna for $4 \mathrm{G} / 5 \mathrm{G}$ and IoT devices using theory of characteristic modes," in International J RF Microwave Computer Aided Eng., vol. 30, pp. 1-19, 2020.

[3] H. Iwasaki and Y. Suzuki, "Dual frequency multilayered circular patch antenna with self-diplexing function," in Electronics Letters, vol 31, pp. 599-601, 13 April 1995.

[4] Younkyu Chung, Seong-Sik Jeon, D. Ahn, Jae-Ick Choi and T. Itoh, "High isolation dual-polarized patch antenna using integrated defected ground structure," in IEEE Microwave and Wireless Components Letters, vol. 14, no. 1, pp. 4-6, Jan. 2004.

[5] L. Inclan-Sanchez, J. Vazquez-Roy and E. Rajo-Iglesias, "High Isolation Proximity Coupled Multilayer Patch Antenna for Dual-Frequency Operation," in IEEE Transactions on Antennas and Propagation, vol. 56, no. 4, pp. 1180-1183, April 2008.

[6] Shih-Hsun Hsu, Yu-Jiun Ren and Kai Chang, "A Dual-Polarized Planar-Array Antenna for S-Band and X-Band Airborne Applications," in IEEE Antennas and Propagation Magazine, vol. 51, no. 4, pp. 70-78, Aug. 2009.

Brazilian Microwave and Optoelectronics Society-SBMO received 13 Feb 2021; for review 25 Feb 2021; accepted 30 May 2021 
Journal of Microwaves, Optoelectronics and Electromagnetic Applications, Vol. 20, No. 3, September 2021

DOI: http://dx.doi.org/10.1590/2179-10742021v20i31213

[7] J. F. Zhang, Y. J. Cheng, Y. R. Ding and C. X. Bai, "A Dual-Band Shared-Aperture Antenna With Large Frequency Ratio, High Aperture Reuse Efficiency, and High Channel Isolation," in IEEE Transactions on Antennas and Propagation, vol. 67, no. 2, pp. 853-860, Feb. 2019.

[8] K. Wang et al., "A Dual-Wideband Dual-Polarized Aperture-Shared Patch Antenna With High Isolation," in IEEE Antennas and Wireless Propagation Letters, vol. 17, no. 5, pp. 735-738, May 2018.

[9] Feng $\mathrm{Xu}$ and $\mathrm{Ke} \mathrm{Wu}$, "Guided-wave and leakage characteristics of substrate integrated waveguide," in IEEE Transactions on Microwave Theory and Techniques, vol. 53, no. 1, pp. 66-73, Jan. 2005.

[10] S. Mukherjee and A. Biswas, "Design of Self-Diplexing Substrate Integrated Waveguide Cavity-Backed Slot Antenna," in IEEE Antennas and Wireless Propagation Letters, vol. 15, pp. 1775-1778, 2016.

[11] A. A. Khan and M. K. Mandal, "Compact Self-Diplexing Antenna Using Dual-Mode SIW Square Cavity," in IEEE Antennas and Wireless Propagation Letters, vol. 18, no. 2, pp. 343-347, Feb. 2019.

[12] D. Chaturvedi, A. Kumar and S. Raghavan, "A Nested SIW Cavity-Backing Antenna for Wi-Fi/ISM Band Applications," in IEEE Transactions on Antennas and Propagation, vol. 67, no. 4, pp. 2775-2780, April 2019.

[13] P. Nigam, A. Muduli, S. Sharma and A. Pal, "SIW Based Dual-Fed Cavity-Backed Self-diplexing Slot Antenna," in Telecommunication and Radio Engineering Journal, vol. 79, no. 16, pp. 1455-1466, Sept. 2020.

[14] P. Nigam, A. Muduli, S. Sharma and A. Pal, "SIW Based Self-Diplexing Dumbbell Slot Antenna for X- Band Application," 2019 Women Institute of Technology Conference on Electrical and Computer Engineering (WITCON ECE), Dehradun Uttarakhand, India, 2019, pp. 231-234.

[15] P. Nigam, A. Muduli, S. Sharma and A. Pal, "The Substrate Integrated Waveguide Based Self- Triplexing Cross Slot Antenna," 2019 Women Institute of Technology Conference on Electrical and Computer Engineering (WITCON ECE), Dehradun Uttarakhand, India, 2019, pp. 241-246.

[16] A. Iqbal, M. A. Selmi, L. F. Abdulrazak, O. A. Saraereh, N. K. Mallat and A. Smida, "A Compact Substrate Integrated Waveguide Cavity-Backed Self-Triplexing Antenna," in IEEE Transactions on Circuits and Systems II: Express Briefs, vol. 67, no. 11, pp. 2362-2366, Nov. 2020.

[17] P. Nigam, R. Agarwal, A. Muduli, S. Sharma, A. Pal, "Substrate integrated waveguide based cavity-backed self-triplexing slot antenna for X-Ku band applications," in International Journal of RF and Microwave Computer Aided Eng., vol. 30, pp.1-11, 2020.

[18] A. Kumar, "Design of self-quadruplexing antenna using substrate integrated waveguide technique," in Microwave and Optical Technology Letter, vol. 61, pp. 2687-2689, 2019.

[19] S. Priya, S. Dwari, K. Kumar and M. K. Mandal, "Compact Self-Quadruplexing SIW Cavity-Backed Slot Antenna," in IEEE Transactions on Antennas and Propagation, vol. 67, no. 10, pp. 6656-6660, Oct. 2019.

[20] Y. Tong, Z. Qian, W. Cao, S. Shi and Y. Cai, "Design of frequency duplex and triplex antennas based on quarter-mode substrate integrated waveguide," in IET Microwaves, Antennas and Propagation, vol. 13, pp. 414-419, 2019.

[21] P. Nigam, A. Muduli, S. Sharma, A. Pal, "The Substrate Integrated Waveguide Based Dumbbell-shaped Self Diplexing Cross Slot Antenna", Advances in Systems Engineering (Springer Nature Singapore) pp. 523-534, 2021.

[22] S. Sharma, P. Nigam, A. Muduli, and A. Pal, "Highly Isolated Self-Multiplexing 5G Antenna for IoT Applications", Blockchain for 5G-Enabled IoT: The new wave for Industrial Automation Springer pp. 593-619, 2021.

[23] T. Deckmyn et al., "A Novel $60 \mathrm{GHz}$ Wideband Coupled Half-Mode/Quarter-Mode Substrate Integrated Waveguide Antenna," in IEEE Transactions on Antennas and Propagation, vol. 65, no. 12, pp. 6915-6926, Dec. 2017.

[24] Bozzi, M., Georgiadis, A. \& Wu K. "Review of substrate-integrated waveguide circuits and antennas". IET Microwaves Antennas \& Propagation, vol. 5, no. 909-920, 2011.

[25] K-D Hong, X. Zhang, L. Zhu, X-K Bi, T. Yuan, "Slot loading effect on impedance and radiation performance of high-gain patch antenna under $\mathrm{TM}_{03}$-mode operation," in International Journal of RF Microwave Computer Aided Eng. 29:e21967, 2019.

[26] Duk-Jae Woo, Taek-Kyung Lee, Jae-Wook Lee, Cheol-Sig Pyo and Won-Kyu Choi, "Novel U-slot and V-slot DGSs for band-stop filter with improved Q factor," in IEEE Transactions on Microwave Theory and Techniques, vol. 54, no. 6, pp. 2840-2847, June 2006.

[27] L. Riaz, U. Naeem and M. F. Shafique, "Miniaturization of SIW Cavity Filters Through Stub Loading," in IEEE Microwave and Wireless Components Letters, vol. 26, no. 12, pp. 981-983, Dec. 2016.

[28] A. Iqbal, A. Bouazizi, S. Kundu, I. Elfergani, J. Rodriguez, "Dielectric resonator antenna with top loaded parasitic strip elements for dual-band operation," in Microwave Optical Technology Letter, vol. 61, pp. 2134-2140, 2019.

[29] W. Che, D. Wang and Y. L. Chow, "Analysis and experiment of substrate integrated waveguide cavity of four sidewalls of cylinders and solid top and bottom walls," in International Journal of Electronics, vol. 95, no.1, pp. 67-76, 2008. 